\title{
Longitudinal and cross-sectional analysis of group performance measures in competitive youth soccer
}

\author{
ALLEN J. SCHUH \\ California State University, Hayward, California
}

\begin{abstract}
The longitudinal research design consisted of a first-year (62 games) and a third-year (47 games) study of a male youth soccer team. During the second year (53 games) of the research, a team of players comparable in skill and age was examined to allow a cross-sectional comparison on the team performance measures. The clearest results were significantly different mean numbers of direct and indirect free kicks, and the numbers of goals scored were significantly more variable in the older age group. One higher-order factor and two second-order orthogonal factors were extracted from each data set. The most interpretable factor was termed game domination: high positive factor loadings were from game measures of shots, goals, corner kicks, and game outcome. High negative loadings were from goalkeeper touches of the ball, goalkeeper saves, and goal kicks.
\end{abstract}

Soccer has been reported to be the most popular athletic sport in the world (Chyzowych, 1978; L. Harris, 1978; International Football Association Board, 1984; Sellin, 1977). It has certainly become a growth sport in the United States. Soccer is considered by parents to be less hazardous than other traditional sports, it allows participation by female and male athletes, and it can be a great body conditioner for young players. Typically, youths can begin playing soccer in organized recreational surroundings even before they enter school. Children may be playing soccer in full uniform with goals set up, fields marked, and paid referees before they can read and write their own names.

An interested researcher can find many discussions of the developmental capacities of youths (Liebert, Poulos, $\&$ Strauss, 1974; Munn, 1974). However, there are no data bases on which team performance measures are likely to be at a high or low level for an age group, how the team performance measures will change with the developing capacities and stature of the players, and how measures of game activity indicate on what measures to focus during scarce practice times.

Data bases reflect the measures of effectiveness that are of concern to researchers. Measures of effectiveness can be dynamic, as has been described in many secondary sources (Anastasi, 1976; Cronbach, 1984; Guion, 1965; McCormick \& Tiffin, 1974; Nunnally, 1970; Siegel \& Lane, 1982). Systematic changes can be expected during the course of a human's development (Ambron \& Brodzinsky, 1979; Liebert et al., 1974; Munn, 1974; Nash, 1978; Ripple, Biehler, \& Jaquish, 1982; Vander Zanden, 1981). Systematic changes occur in all sports and relate to measures of effectiveness in those sports (Carter \&

\footnotetext{
The author's mailing address is Department of Management Sciences, School of Business and Economics, California State University, Hayward, CA 94542-3069.
}

Machol, 1978; Cook, 1977; D'Esopo \& Lefkowitz, 1977; Lindsey, 1977; Machol, Ladany, \& Morrison, 1976; Mitchell \& Michel, 1977; Pollard, Benjamin, \& Reep, 1977; Price \& Rao, 1977). Also, there are many decisions relating to team structure that depend on knowledge of what changes in performance measurement will occur (Dalton, Todor, Spendolini, Fielding, \& Porter, 1980; Dyer, Miller, \& Morse, 1978; Gagne, 1962; Huber, Ullman, \& Leifer, 1974; Mitchell \& Michel, 1977; Price \& Rao, 1977).

The analysis of team data makes special demands on the researcher, because the classification of tasks and the evaluation of an individual player's performance is not independent of the effort of others. Team effectiveness in maneuvers is dependent upon the cooperative efforts of three or more persons (Bass \& Vaughan, 1966; J. P. Campbell, 1971; Dyer et al., 1978; Gagne, 1962; Guion, 1965; Machol et al., 1976; McCormick \& Tiffin, 1974; Siegel \& Lane, 1982). In soccer, as in many organized activities, the unit must work truly as a team to prevent the opponent from scoring (Chyzowych, 1978; Hughes, 1973; Jones \& Welton, 1979; Schmid, McKeon, \& Schmid, 1968; Sellin, 1976, 1977; Vogelsinger, 1982).

The purpose of this report is to describe an analysis of a 3-year span in which one team was studied first as players under the age of 12 years and again 2 years later, when they were at the top of the under-14-years-of-age bracket. The study was performed in hopes that the longitudinal comparison would reflect which performance measures change with developing player attitude, knowledge, and skill. Some changes may be erroneously attributed to increasing player age. The cross-sectional sample consisted of players matched with subjects of the longitudinal study for age and skill and from the same hometown. They were studied during the 2nd year of the 3-year study. Thus, results holding up both longitudinally and cross-sectionally should reflect actual differences in development. 


\section{METHOD}

\section{Participants}

Participants were 16 male residents of Pleasanton, California (population 40,000), born in 1973 or 1974, and selected during league tryouts from a pool of enrolled male soccer players who had at least 1 year of previous experience. The team (Ballistic United Soccer Club or BUSC) practiced about $4 \mathrm{~h}$ a week and played their games on the weekends and holidays.

\section{Data Recorded}

Records were kept for all games in which goals were set up with nets, the fields marked, and referees assigned. Games lasted 60-70 min depending upon player age. Records were kept on number of goals scored, game outcome (wins/ties/losses), number of times the goalkeeper played the ball, number of saves by the goalkeeper, number of goal kicks by each team, number of corner kicks, number of direct free kicks awarded because of fouls, number of indirect free kicks awarded for minor infractions, number of times the team was awarded ball possession because the other team was offsides, and number of throw-ins. A full description of these measures is provided by several authors (Chyzowych, 1978; L. Harris, 1978; P. E. Harris \& L. R. Harris, 1983; Hughes, 1973; International Football Association Board, 1984; Jones \& Welton, 1979; Lover, 1975, 1978, 1980; Schmid et al., 1968).

\section{Analysis Procedures}

To perform the longitudinal research, I collected data for first-year (62 games) and third-year (47 games) seasons of the same basic team of players. The team during the 1st study year is designated Group A; the team of 2 years later is referred to as Group B. During the intervening year, while Group A matured to become Group B, the author studied Group C (53 games), which consisted of the same number of players from the same hometown, who were comparable in skill and age to players of Group B during the third year of the study. Thus, the design of the study had both longitudinal and cross-sectional elements. The data comparison may be considered inexact in that Group A differs from Group B due to player replacements. Some players did not maintain sufficient relative playing ability to survive the yearly tryouts, and some players moved. Also, 1 player made all three teams. I am aware of a good discussion of the criticisms of the design (D. T. Campbell \& Stanley, 1963).

Means and standard deviations were calculated for the performance measures of game activity for all games within blocks pooled. For each separate group, a principal factor analysis, with varimax rotation, was conducted. The varimax rotation was subjected to a hierarchical analysis to remove the higher-order and second-order factors (Harman, 1967; Wherry, 1959, 1984).

\section{RESULTS}

Mean performance on the measures of effectiveness for each block of data is shown in Table 1 . It can be seen that only two measures met the criteria of (1) showing a significant difference between Groups A and B, (2) showing a similar difference between Groups A and C, and (3) showing no difference between Groups B and C. These criteria help clarify the nature of developmental change. The two measures that met the criteria were the direct free kicks ( $t$ for the AB comparison was 3.54, $p<.01 ; t$ for the AC comparison was $4.95, p<.01$; and $t$ for the $\mathrm{BC}$ comparison was -.48, n.s.) and indirect free kicks other than for offsides $(t$ for the AB comparison was $4.41, p<.01 ; t$ for the BC comparison was $2.60, p<.01$; and $t$ for the BC comparison was 1.86 , n.s.; Hays, 1973; McNemar, 1969; Sockloff \& Edney, 1972). Three measures-goalkeeper touches, goalkeeper saves, and goal kicks-were significant on one or more
Table 1

Means and $t$ Tests for Performance Measures

\begin{tabular}{|c|c|c|c|c|c|c|}
\hline \multirow[b]{2}{*}{ Variable Name } & \multicolumn{3}{|c|}{ Means } & \multicolumn{3}{|c|}{$t$ Tests } \\
\hline & A & B & $\mathrm{C}$ & $\mathrm{AB}$ & $\mathrm{AC}$ & $\mathrm{BC}$ \\
\hline Shots & 11.50 & 12.10 & 10.65 & .28 & -.86 & 1.48 \\
\hline Goals & 2.13 & 1.93 & 1.86 & -.68 & -.88 & .24 \\
\hline \multicolumn{7}{|l|}{ Goalkeeper } \\
\hline Touches & 11.66 & 15.28 & 13.12 & $5.12 \dagger$ & $2.15^{*}$ & $2.77 \dagger$ \\
\hline \multicolumn{7}{|l|}{ Goalkeeper } \\
\hline Saves & 4.19 & 5.03 & 4.76 & $2.01 *$ & 1.44 & .59 \\
\hline Goal Kicks & 6.18 & 6.63 & 7.38 & .82 & $2.32 *$ & -.81 \\
\hline Corner Kicks & 2.58 & 3.27 & 3.17 & 1.94 & 1.85 & .29 \\
\hline \multicolumn{7}{|l|}{ Direct Free } \\
\hline Kicks & 5.08 & 7.04 & 7.33 & $3.54 \dagger$ & $4.95 \dagger$ & -.48 \\
\hline \multicolumn{7}{|l|}{ Indirect Free } \\
\hline Kicks & .68 & 1.35 & 1.04 & $4.41 \dagger$ & $2.60 \dagger$ & 1.86 \\
\hline Offsides & 1.32 & 1.56 & 1.49 & .81 & .65 & .23 \\
\hline Throw-ins & 20.47 & 19.91 & 21.84 & -.63 & -1.31 & 1.90 \\
\hline Sample & 124 & 94 & 106 & - & - & - \\
\hline
\end{tabular}

comparisons but did not meet the criteria for triangulating on a developmental change.

Table 2 shows the standard deviations and significance tests for differences in variances. Only one variable met the criteria for triangulating on a developmental change: goals ( $F$ for the $\mathrm{AB}$ comparison was $2.02, p<.01 ; F$ for the AC comparison was $1.52, p<.05$; and $F$ for the BC comparison was 1.33 , n.s.). Four other measuresshots, direct free kicks, offsides, and throw-ins-were significant on one or more comparisons but did not meet the criteria for triangulation on a developmental change.

Table 3 shows the results of the hierarchical factor analysis. When each data set was compared, one easily interpretable factor was present: a reflection of game domination. High positive factor loadings were from the game measures of shots, goals, corners, and wins/ties/losses. High negative factor loadings on the same dimension were from goalkeeper touches, goalkeeper saves, and goal kicks. The other second-order factor and the hierarchical dimension were more difficult to interpret. Indeed,

Table 2

Standard Deviations and $\boldsymbol{F}$ Tests for Performance Measures

\begin{tabular}{|c|c|c|c|c|c|c|}
\hline \multirow[b]{2}{*}{ Variable Name } & \multicolumn{3}{|c|}{ Standard Deviations } & \multicolumn{3}{|c|}{$F$ Tests } \\
\hline & A & B & $\mathrm{C}$ & AB & $\mathrm{AC}$ & BC \\
\hline Shots & 8.36 & 7.19 & 6.62 & 1.35 & $1.59 *$ & 1.17 \\
\hline Goals & 2.55 & 1.79 & 2.07 & $2.02 \dagger$ & $1.52 *$ & 1.33 \\
\hline \multicolumn{7}{|l|}{ Goalkeeper } \\
\hline Touches & 4.67 & 5.53 & 5.49 & 1.40 & 1.37 & 1.01 \\
\hline \multicolumn{7}{|l|}{ Goalkeeper } \\
\hline Saves & 2.79 & 3.22 & 3.15 & 1.32 & 1.26 & 1.04 \\
\hline Goal Kicks & 4.03 & 4.03 & 3.81 & 1.00 & 1.11 & 1.11 \\
\hline Corner Kicks & 2.44 & 2.69 & 2.32 & 1.21 & 1.11 & 1.34 \\
\hline Direct Free & & & & & & \\
\hline Kicks & 3.20 & 4.60 & 3.63 & $2.06 t$ & 1.28 & $1.61 *$ \\
\hline Indirect Free & & & & & & \\
\hline Kicks & 1.02 & 1.19 & 1.11 & 1.25 & 1.18 & 1.13 \\
\hline Offsides & 1.83 & 2.37 & 2.05 & $1.68 *$ & 1.26 & 1.33 \\
\hline Throw-ins & 7.16 & 5.80 & 8.47 & $1.52 *$ & 1.39 & $2.13 \dagger$ \\
\hline Sample & 124 & 94 & 106 & - & - & 一 \\
\hline
\end{tabular}


Table 3

Higher and Secondary Factor Loadings

\begin{tabular}{|c|c|c|c|c|c|c|c|c|c|}
\hline \multirow[b]{4}{*}{ Variable Name } & \multicolumn{9}{|c|}{ Group } \\
\hline & \multirow[b]{3}{*}{ Higher } & \multicolumn{2}{|l|}{ A } & \multicolumn{3}{|c|}{ B } & \multicolumn{3}{|c|}{ C } \\
\hline & & \multicolumn{2}{|c|}{ Secondary } & \multicolumn{3}{|c|}{ Secondary } & \multirow[b]{2}{*}{ Higher } & \multicolumn{2}{|c|}{ Secondary } \\
\hline & & 1 & 2 & Higher & 1 & 2 & & 1 & 2 \\
\hline Shots & .20 & .23 & .83 & .56 & .79 & .10 & -.28 & .54 & .19 \\
\hline oals & .20 & .24 & .83 & .42 & .51 & .16 & -.2 .29 & .53 & 16 \\
\hline \multicolumn{10}{|l|}{ Goalkeeper } \\
\hline Touches & .00 & -.36 & -.36 & -.23 & -.29 & -.08 & .29 & -.53 & -.1 \\
\hline \multicolumn{10}{|l|}{ Goalkeeper } \\
\hline Saves & -.09 & -.16 & -.43 & -.26 & -.43 & .00 & .27 & -.53 & -.19 \\
\hline Goal Kicks & -.08 & -.27 & -.50 & -.26 & -.44 & .02 & .28 & -.39 & -.04 \\
\hline Corner Kicks & .08 & .27 & .51 & .42 & .47 & .20 & -.09 & .32 & .21 \\
\hline \multicolumn{10}{|l|}{ Direct Free } \\
\hline Kicks & -.03 & -.06 & -.16 & -.14 & .11 & -.34 & .12 & -.09 & .0 \\
\hline \multicolumn{10}{|l|}{ Indirect Free } \\
\hline Kicks & -.01 & .00 & -.05 & -.12 & .03 & -.22 & .26 & -.07 & .25 \\
\hline Offsides & .13 & -.69 & -.30 & -.18 & -.15 & -.14 & -.05 & -.30 & -.37 \\
\hline Throw-ins & -.09 & .27 & .00 & .22 & .16 & .18 & .23 & .09 & .38 \\
\hline Win-Loss & .06 & .45 & .62 & .35 & .27 & .29 & -.16 & .49 & .29 \\
\hline Sample & 124 & - & - & 94 & - & - & 106 & - & - \\
\hline
\end{tabular}

the higher-order factor for Group A had no factor coefficient over .20. Since all data sets had this one gamedomination factor, it was not seen as a developmental change.

\section{DISCUSSION}

The analysis showed several things that most observers of the sport had probably assumed. The mean differences for direct and indirect free kicks reflect the significantly greater number of referee calls for fouls and infractions when the players move to the older age group. The measures have in common greater referee control of the game, which is frequently needed as the players develop physically more aggressive mannerisms. If it is true that the development of soccer players between these two ages is accounted for by changes in knowledge, attitude, and skill, then it is likely that the greater frequency of referee calls is due to bad attitude displayed on the field. It is a common club practice to assign more experienced referees to the older age groups, and these data suggest that the practice should continue.

Other differences did not meet the criteria imposed on the data set to indicate developmental differences. Goalkeeper touches of the ball were significantly different by every comparison, so there is confusion as to how much the differences are due to development and how much to differing coaching philosophies. Perhaps the goalkeepers who attend special summer goalkeeper training camps are exposed to different philosophies on how much they should be involved in the game. Some say the goalkeeper should stay in the goal area, and others say he should roam the penalty area freely and touch the ball often. Whatever the cause, there is too much variance to be attributable to the single source of player development. Different coaching philosophies would confound the developmental trend. Goalkeeper saves was significantly different for the one comparison longitudinally, but not cross-sectionally. Goal kicks were different cross-sectionally, but not longitudinally. Future research will be needed to judge the meaning of these results.

In the comparisons of the standard deviations, only one measure, goals, met the criteria. Thus, the mean number of goals were statistically the same, but the variability of the goals increased developmentally. Shots were different cross-sectionally, but not longitudinally. Direct free kicks, offsides calls, and throw-ins were significantly different longitudinally, but not cross-sectionally. Thus, it is not known how much of the apparent difference is due to differences in referees for the matches or, in the case of throw-ins, how much variability is due to the sizes of the fields on which the games were played. Again, more research is needed.
The principal factor analysis, rotated to varimax and then to a hierarchical solution, showed one interpretable factor, which the author calls game domination (i.e., winning by a team due to success at all aspects of the game, not simply from scoring goals). The high positive factor loadings on shots, goals, and corners refer to the actions of players at the attacking third of the field. The high negative factor loadings on the same dimension were from goalkeeper touches, goalkeeper saves, and goal kicks, or the actions that occur in the defending third of the playing field. The fact that these performance measures load clearly on the same factor with the measure of game outcome suggests strongly that winning occurs many places on the field. Observers sometimes notice one team's game dominance, which is marked by the ball's staying in the attacking third of the field. As these research results show, performance on things that occur in the attacking third, and avoidance of things that occur in the defending third, are related to winning.

The results reported here are for youthful players rapidly approaching maturity. Whether the findings would hold for older players or in other settings remains to be investigated. Continuing to measure developmental changes will help explain the progress of differences we see as players mature and advance in their age groups. Further investigation should go beyond the standard measures of game performance reported here. These measures were simple and straightforward: If the ball went into touch and the referee awarded possession to the other team, the data recorder simply wrote down this objective measure. The next steps in research should be to derive other indexes of game activity that do not come off the traditional score card. If we had such measures, we might better explain the world's most popular game activity for the benefit of players, coaches, referees, league officials, and spectators.

\section{REFERENCES}

Ambron, S. R., \& Brodzinsky, D. (1979). Lifespan human development. New York: Holt, Rinehart \& Winston.

AnAstasi, A. (1976). Psychological testing. New York: Macmillan. Bass, B. M., \& Vaughan, J. A. (1966). Training in industry: The psychology of learning. Belmont, CA: Wadsworth.

CAmpbell, D. T., \& Stanley, J. C. (1963). Experimental and quasiexperimental designs for research. Chicago: Rand McNally.

CAmpBell, J. P. (1971). Personnel training and development. Annual Review of Psychology, 22, 565-602.

Carter, V., \& Machol, R. E. (1978). Optimal strategies on fourth down. Management Science, 24, 1758-1762.

CHYzowych, W. (1978). The official soccer book of the United States Soccer Federation. New York: Rand McNally. 
Cook, E. (1977). An analysis of baseball as a game of chance by the Monte Carlo method. In S. P. Ladany \& R. E. Machol (Eds.), Optimal strategies in sports (pp. 50-54). Amsterdam: North-Holland.

CRONBACH, L. J. (1984). Essentials of psychological testing. New York: Harper \& Row.

Dalton, D. R., Todor, W. D., Spendolini, M. J., Fielding, G. J., \& PORTER, L. W. (1980). Organizational structure and performance: A critical review. Academy of Management Review, 5, 49-64.

D'Esopo, D. A., \& LEFKowITZ, B. (1977). The distribution of runs in the game of baseball. In S. P. Ladany \& R. E. Machol (Eds.), Optimal strategies in sports (pp. 55-62). Amsterdam: North-Holland.

Dyer, J. S., Miller, R. A., \& Morse, J. J. (1978). A framework for the study of work settings. Management Science, 24, 1393-1403.

GAGNE, R. M. (Ed.). (1962). Psychological principles in system development. New York: Holt, Rinehart \& Winston.

Guion, R. M. (1965). Personnel testing. New York: McGraw-Hill.

Harman, H. H. (1967). Modern factor analysis. Chicago: University of Chicago Press.

HARRIS, L. (1978). Futbol means soccer: Easy steps to understanding the game of soccer. Manhattan Beach, CA: Soccer for Americans.

HARRIS, P. E., JR., \& HARRIS, L. R. (1983). Fair or foul: The complete guide to soccer officiating in America. Manhattan Beach, CA: Soccer for Americans.

HAYS, W. L. (1973). Statistics for the social sciences. New York: Holt, Rinehart \& Winston.

Huber, G. P., Ullman, J., \& Leifer, R. (1974). Optimum organization design: An analytic-adoptive approach. Academy of Management Review, 4, 567-578.

Hughes, C. F. C. (1973). Soccer tactics and teamwork. Wakefield, South Yorkshire, England: EP Publishing.

INTERNATIONAL FoOtBall AsSOCIATION BOARD. (1984). Laws of the game and universal guide for referees. New York: United States Soccer Federation.

Jones, K., \& Welton, P. (1979). Soccer skills \& tactics. New York: Crown.

Liebert, R. M., Poulos, R. W., \& Strauss, G. D. (1974). Developmental psychology. Englewood Cliffs, NJ: Prentice-Hall.

LindSEY, G. R. (1977). A scientific approach to strategy in baseball. In S. P. Ladany \& R. E. Machol (Eds.), Optimal strategies in sports (pp. 1-30). Amsterdam: North-Holland.

LOVER, S. F. (1975). Association football laws illustrated. London: Pelham Books.

LOVER, S. F. (1978). Association football match control: An illustrated handbook for the football referee. London: Pelham Books.

LOVER, S. F. (1980). The illustrated soccer quiz book. Chicago: Rand McNally.

Machol, R. E., Ladany, S. P., \& Morrison, D. G. (Eds.). (1976). Management science in sports. Amsterdam: North-Holland.
McCormick, E. J., \& Tiffin, J. (1974). Industrial psychology. Englewood Cliffs, NJ: Prentice-Hall.

McNemar, Q. (1969). Psychological statistics. New York: Wiley.

Mitchell, C. R., \& Michel, A. J. (1977). The valuation of a baseball player. In S. P. Ladany \& R. E. Machol (Eds.), Optimal strategies in sports (pp. 42-45). Amsterdam: North-Holland.

MunN, N. L. (1974). The growth of human behavior. Boston: Houghton Mifflin.

Nash, J. (1978). Developmental psychology. Englewood Cliffs, NJ: Prentice-Hall.

NUNNALLY, J. C., JR. (1970). Introduction to psychological measurement. New York: McGraw-Hill.

Pollard, R., Benjamin, B., \& Reep, C. (1977). Sport and the negative binomial distribution. In S. P. Ladany \& R. E. Machol (Eds.), Optimal strategies in sports (pp. 188-195). Amsterdam: NorthHolland.

Price, B., \& RaO, A. G. (1977). A model for evaluating player performance in professional basketball. In S. P. Ladany \& R. E. Machol (Eds.), Optimal strategies in sports (pp. 116-122). Amsterdam: NorthHolland.

Ripple, R. E., Biehler, R. F., \& JAQuish, G. A. (1982). Human development. Boston: Houghton Mifflin.

Schmid, I. R., McKeon, J. L., \& Schmid, M. R. (1968). Skills and strategies of successful soccer. Englewood Cliffs, NJ: Prentice-Hall.

SEllin, E. (1976). The inner game of soccer. Mountain View, CA: World Publications.

Sellin, E. (1977). Soccer basics. Mountain View, CA: World Publications.

SiEgEL, L., \& LANE, I. M. (1982). Personnel and organizational psychology. Homewood, IL: Irwin.

SocklofF, A. J., \& EDNEY, J. N. (1972). Some extension of Student's $t$ and Pearson's $r$ central distributions. Philadelphia, PA: Temple University, Measurement and Research Center.

Vander Zanden, J. W. (1981). Human development. New York: Knopf.

VOGELSINGER, H. (1982). The challenge of soccer: A handbook of skills, techniques, and strategy. La Jolla, CA: Inswinger.

WHERRY, R. J. (1959). Hierarchical factor solutions without rotation. Psychometrika, 24, 45-51.

WhERRY, R. J. (1984). Contributions to correlational analysis. New York: Academic Press.

(Manuscript received for publication September 11, 1987.) 